To be presented at the 306 th meeting of the

American Institute of Electrical Engineers,

Cleveland, O., March 18-19, 1915.

Copyright 1915 . By A. I. E. E.

(Subject to final revision for the Transactions.)

\title{
ANSWERS TO SOME QUESTIONS ON ELECTRIC ARC WELDING
}

\author{
BY J. F. LINCOLN
}

\section{Abstract of Paper}

The paper contains a general description of the process of electric arc welding and discusses some of the general principles involved in this work. Some of the principal difficulties encountered in electric arc welding are described and comparison is made of its advantages over other methods of welding. The author concludes that there are very few cases of welding which cannot be more satisfactorily done with the electric arc than by any other means, provided the operator is sufficiently skillful. $\mathrm{He}$ also considers that less practise is required by operators to make successful electrical welds than is necessary with any other process. The paper concludes with some operating costs of different types of electric arc welding machines.

FOR A PROCESS of such great importance as arc welding, surprisingly little is known regarding it among many manufacturers who could apply it to advantage in their work. The available literature on this subject is very incomplete, and gives but little information to the man who might apply arc welding to his product. It is the object of this paper to consider the fundamental principles of arc welding of metals so that the manufacturer can decide for himself the following questions which may arise in connection with the work in his own plant.

1. What metals can be welded by the electric arc?

2. What difficulties are encountered in electric arc welding?

3 . What is the strength of the weld in comparison with the original piece?

4. What is the cost of welding?

5 . What is the function of the arc welding machine?

6. How does electric welding compare with oxy-acetylene and other similar methods?

There are many concerns that could use electric arc welding to great advantage but which are overlooking its possibilities because of insufficient knowledge in regard to it.

All metals can be welded. Any two pieces of metal which are brought into contact at their melting temperature will adhere so

Manuscript of this paper was received February 3, 1915. 
that they are no more liable to break at the point of junction than at any other point. This is a well-known property of all metals and the welding process, therefore, is very frequently applied. The electric arc is used in connection with the process merely as a heating agent, and this is its only function in connection with the process. It is superior to any other method of heating because of its ease of application and the economy with which heat can be concentrated at any given point by its use. There are no conditions in connection with arc welding to which these principles do not apply: viz., that metals at a welding temperature will adhere, and that the electric arc will most economically and easily furnish the heat to bring them to this welding temperature.

The difficulties which are encountered in welding are the following: Formation of oxide; expansion and contraction under heat; burning through.

In the case of brass or zinc, the heated parts will be covered with a coat of oxide before they come to a welding temperature. This zinc oxide makes it impossible for two clean surfaces of the metal to come into intimate contact. It follows that some method must be adopted for disposing of this oxide at the weld and allowing the two surfaces to be welded to come together without the possibility of oxide being included between them. This condition obtains in the welding of aluminum and of a great many alloys. In order to eliminate this coat of oxide it is usually necessary to puddle the weld, that is, to have enough of the metal melted at the weld so that the oxide is floated away from it. When this is done, the two surfaces which are to be welded are covered by a coat of melted metal on which the oxide floats, thus allowing two clean surfaces of metal to come together. This precaution, however, in case of steel, to which welding is applied to a greater extent than to any other metal, is not usually necessary.

Another difficulty which is encountered in the welding of a great many metals is their considerable expansion under heat which results in a corresponding contraction when the weld cools, so that internal stresses are introduced which in extreme cases will result in cracking the metal at or near the weld. To eliminate this possibility, it is necessary, depending on the shape of the piece, to apply heat either all over the piece to be welded or at certain points, so that the uneven contraction giving rise to internal stresses will be avoided. In the case of cast iron, it is 
often necessary to anneal after welding, since otherwise the welded piece will be glass hard on account of chilling.

Another difficulty with arc welding is that very thin pieces of metal which are to be welded together and which are not backed up by something to carry away the heat, are very liable to burn through, leaving holes where the weld should be. This difficulty can be avoided by backing up the weld with a metal face, or by decreasing the intensity of the arc so that the melting through will not occur. The practical limiting thinness of metal to which arc welding can be applied without metallic backing is approximately 22 gage, although thinner metals than this can be welded if the operator is very skillful.

The next difficulty with arc welding is the lack of skillful operators. Manufacturers in a great many cases look upon arc welding as being very complicated, and are very apt to become discouraged with the results of unskilled operators. They sometimes do not guve the operators a chance to master the process before making up their minds that the method is not feasible. If the same point of view were held by manufacturers in regard to welding by means of the forge fire, blacksmithing would never have come to be practised, and a broken piece of steel would always remain a piece of scrap. It does not require anything like as skillful handling to make a good arc weld as it does to make a weld on an anvil, and there are very few electric welds that cannot be handled successfully by an operator of average intelligence with one week's instruct:on, although his work will become better in quality and finish as he continues to gain experience.

Next comes the most important question of all; that is, what is the strength of the weld? The answer is that the strength of the weld is equal to that of the metal of which the weld is made. It should be remembered, however, that the metal which goes into the weld is really a casting, and has not been rolled. This means that ihe strength of the weld would be equal to that of the same metal that is used for filling, if used in the form of a casting. For example, two pieces of steel could be welded producing a tensile strength at the weld of at least $50,000 \mathrm{lb}$. per sq. in. Higher tensile strength than this can be obtained by the use of special alloys for the filling material, or by rolling the weld. Tensile strength as great as mentioned will give a result which is perfectly satisfactory in almost all cases.

There are a great many welds where it is possible to build up, 
that is, to make the section at the weld a little larger than the section of the rest of the piece. By doing this, the disadvantage of the weld being in the form of a casting while the rest of the piece is in the form of rolled steel can be overcome, and the weld itself will be even stronger than the original piece.

The next question of importance to the man contemplating a new application of welding is, what is the adaptability of electric arc welding to my work in comparison with anvil welds, acetylene welds or some other method? This is somewhat difficult to answer comprehensively. There are no doubt some cases where the use of a drop hammer and a forge fire and the oxy-acetylene blow torch will make, all things considered, a better job than the use of the electric arc, although cases where this has been conclusively proved are extremely rare. The electric arc will melt metal in a weld for from 3 to 30 per cent of the cost of melting it with the oxy-acetylene blow torch, on account of the fact that the heat can be applied exactly where it is required, and in any amount that it is required.

Let us now consider some of the essential features of various types of arc welding machines which are in use. The three most important considerations in the design of the welding machine are: (1) the variation of the supply voltage as required by the arc; (2) power economy; and (3) conversion from alternating- to direct-current energy. It is practically out of the question to apply the alternating current to arc welding since one electrode must always remain positive. In arc welding by means of the carbon arc, the piece to be welded is made the positive electrode, while in welding with a metallic arc either the piece to be welded or the piece used as a filler may be made the positive electrode.

The voltage across the arc is a variable quantity depending on the length and temperature of the arc and the gases in it. With a carbon electrode the voltage will vary from 0 to 45 volts. With the metallic electrode the voltage will vary from 0 to 30 volts. It is therefore, necessary for the welding machine to be able to furnish the arc with a current which can be varied as required both in quantity and voltage.

The simplest welding machine is an ohmic resistance in series with the arc. This is entirely satisfactory except, in regard to the cost of current. By the use of resistance in series with the arc on a 220-volt supply circuit, from 80 to 
90 per cent of the current is dissipated in heat in the resistance. Another disadvantage is the fact that most resistances will change with the temperature, thus making the amount of current delivered to the arc a variable quantity. There have been various methods devised for saving the power lost in the series resistance, and a good many machines designed for this purpose have been put on the market.

Practically all arc welding machines now in use consist of motor-generator sets, the motor of which is adapted to the existing supply circuit, and is direct connected to a compoundwound generator delivering current at approximately 75 volts. This current is applied to the arc in series with a resistance. It is evident that since the voltage across the arc will vary from 0 to 50 that from 75 to 25 volts must be dissipated in the resistance, although a considerable saving is effected over the use of a resistance in series with the full supply voltage. It is possible to construct a machine that will eliminate these losses by avoiding the use of a resistance in series with the arc. A machine of this kind will save its cost within a very short time, provided the welder is in steady use.

The following figures give the approximate cost of power for operating arc welding machines under average conditions, which are assumed as follows:

Cost of current, 2 cents per kw-hr.; metallic electrode arc of 150 amperes; carbon arc of 500 amperes; voltage across the metallic electrode arc 20; voltage across the carbon arc 35 ; supply circuit 220 volts direct current; a single resistance in series with the arc.

With the metallic electrode, the cost of energy will be 66 cents per hour. With the carbon electrode $\$ 2.20$ per hour. If a motor-generator set with a 75 -volt constant potential machine is used for a welder, the cost will be for the metallic electrode 25.2 cents per $\mathrm{hr}$., and for the carbon electrode 84 cents per hour.

With a machine which will deliver the required voltage at the arc without the use of a series resistance the cost will be for the metallic electrode, 7.2 cents per hour, and for the carbon electrode 42 cents per hour. These figures assume that the arc is held continuously at its full value. This condition, however, is impossible in practise, and the actual load factor is approximately 50 per cent, which means that, as a welder is usually operated, the actual cost of operation will be about one-half 
of the amounts given above. It is evident, therefore, that it will not take very long to save the cost of a welding machine if all the power wasted in resistance could be saved.

Electric arc welding has not received the attention it deserves and large economies would probably result from its use in many metal working industries. Its adoption merits the serious consideration of all metal workers. 